\title{
O conceito de ficção em Hayden White e sua validade para os debates em história e literatura
}

Henrique Carvalho Pereira

\section{Resumo}

Este artigo tem como objetivo discutir a conceptualização de ficção presente no trabalho do estudioso norte-americano Hayden White. Acredita-se que a discussão possa oferecer contribuições tanto no campo da história como no da teoria literária. O texto central utilizado foi "The fictions of factual representation" (WHITE, I985), que se buscou aqui iluminar a partir das teorias desenvolvidas pelo formalismo russo. O texto começará analisando a conceituação oferecida por White, definirá ficção e, por fim, retornará a White para discutir se é ou não possível considerar a história como "ficção do fato", e o que isso implica.

Palavras-chave: Teoria literária - História - Hayden White - Ficção. 


\section{Considerações iniciais}

A produção teórica de Hayden White (HW, a partir daqui) trouxe diversas inquietações ao ambiente historiográfico. Parece, contudo, curioso que um trabalho que se debruça sobre os limites da literatura não tenha tido tanto impacto na crítica literária. A explicação se torna clara após a leitura de seus textos: não há nada sendo revisto ou questionado no campo da literatura, mas sim no da história. Antes de se encontrarem pontos cegos ou problemas conceituais em sua trajetória, o autor demonstra plena consciência e domínio sobre o que trabalha. Não é isso que explica seu fraco eco na teoria da literatura, mas a concentração mais em temas próprios da história do que da literatura. No entanto, passa nas entrelinhas de seu trabalho a consciência sobre um conceito-chave para suas reflexões, que só pode ser exumado com ajuda da teoria literária.

Trata-se da ideia de ficção. Em seus primeiros trabalhos, HW não define com clareza esse termo. A intenção do presente artigo é procurá-la no texto a ser analisado e desenvolvê-la. Na bibliografia selecionada sobre formalismo russo residem, acredita-se, alguns pontos fundamentais dos quais se espraia a teoria de HW. Com isso, será estudado se a ideia trazida pelo autor se sustenta ou não para se referir à história e, então, serão sugeridas algumas consequências desse raciocínio.

A escolha da bibliografia se baseou na maneira como HW se localiza na crítica. No texto que ocupa aqui o papel central, "The fictions of factual representation" ${ }^{1}$, o autor se situa no momento final do estruturalismo. As noções dessa corrente sobre literatura e ficção vêm dos avanços conjuntos da linguística e da literatura a partir dos anos I9IO, com base nas teorias desenvolvidas no século XIX. A bibliografia utilizada é a bibliografia básica dessa abordagem. Ao término deste texto, espera-se ter encontrado a maneira como se pode entender ficção a partir da "aventura estruturalista" (termo cunhado por Paul, 2OII) de HW e se ela cabe ou não para designar a história, assim assinalando quais as consequências dessa conclusão. Não será discutido o estruturalismo propriamente dito, e será feito um breve sumário do conceito romântico de "arte pela arte". O objetivo deste artigo é entender o conceito de ficção em HW à luz da noção de arte desenvolvida pelo formalismo e os efeitos disso na representação histórica.

I Aqui, citada a edição de 1985 . 


\section{A questão da ficção em "The fictions of factual representation"}

Desde que analisou os grandes clássicos de história do século XIX, HW (1973) insiste que a ficcionalidade se apresenta principalmente pela questão da linguagem, em que o florescimento de figuras de linguagem (tropoi) é inevitável em qualquer discurso e que se apresenta como ponto central para aquele que busca explicar o passado. A inovação está na maneira de narrar e a escolha de uma entre outras, todas precisas em termos de arquivos, se deve a preferências apenas morais, estéticas e políticas. Mais adiante, ele se defronta com a questão da ficção e, retornando ao aspecto linguístico do trabalho de historiador, decide chamá-lo de "ficção do fato".

O argumento de que é possível identificar os textos poéticos com os de história tem como eixo a identidade linguística entre ambos (WHITE, 1985). Para HW, os dois têm como objetivo apresentar uma imagem verbal da realidade, e se definem não por sua "verdade de correspondência [com os fatos]", mas por sua "verdade de coerência [interna do texto]" (WHITE, I985, p. I22, tradução nossa) $)^{2}$. Com o intuito de demonstrar isso, ele narra como a história já esteve equiparada à poética e à retórica na Antiguidade greco-romana e no Renascimento e como foi colocada em outro campo pela sociedade burguesa. O autor recorre, então, à ideia de belles-lettres, que é alterada pelo positivismo para justificar as formas de conhecimento na sociedade burguesa e demonstra como essa mudança no conceito de história se deveu a objetivos políticos. Para ele, todavia, a questão é epistemológica: tanto o historiador quanto o poeta têm como objetivo atingir uma verdade maior que não é necessariamente explicitada em seu texto. Ambos o fazem apresentando uma imagem verbal da realidade. HW coloca que os positivistas e naturalistas (com possível exceção de J. G. Droysen) não perceberam que os eventos não podem falar por si próprios. Nisso, ele retoma uma tese apresentada em um ensaio anterior, "The historical text as literary artifact" (WHITE, I985), em que analisa Robin George Collingwood e aponta que nenhum amontoado de fatos postos em sequência constitui uma história, e que é necessário uni-los por um fio de sentido criado semiologicamente pelo autor. Isso implica que é necessário criar para que se tenha um sentido na história.

Esse recurso a paradigmas ultrapassados conduz HW a questionar o reacionarismo de sua própria posição, e ele localiza a si mesmo no debate estru-

2 No original, "truth of correspondence" e "truth of coherence". 
turalista da teoria literária. Esse raciocínio motivou seu livro de I973, cuja constatação de maior efeito foi o estabelecimento das categorias da narrativa histórica, que se combinam para formar o estilo de cada autor. Para HW (I973; I985), importa o fato de que as representações textuais da realidade (quaisquer que elas sejam) se estabelecem a partir de construções linguísticas e figurativas que revelam uma interpretação, constituindo-se como criações sobre a realidade. Consequentemente, se é necessário dar acabamento e liga no discurso a eventos do passado, esses são reflexos de posições particulares e não de verdades científicas.

O autor recai então na diferenciação entre história e filosofia da história, campos que o interessaram em seu livro de I973. Ambas as formas de se discutir o passado, para ele, se apresentam com uma única diferença de linguagem que realiza o deslocamento de um texto para o outro. A saber: a segunda tem mais enfoque na função metalinguística, ou seja, discute o código e a linguagem que se devem utilizar na discussão da história, e a primeira traz o aspecto teórico como um molde do texto. Para HW, se a filosofia da história é de função metalinguística, a história necessariamente volta-se para a mensagem e tem função poética. Essa discussão ficará mais clara adiante, em Jakobson, mas vale ser ressaltada aqui como pedra de toque.

$\mathrm{O}$ aspecto em relevo no texto de HW, até então, é a ideia de que a história se apresenta no domínio da imaginação. A escolha das figuras de linguagem está relacionada à maneira como se pensam ou imaginam os eventos narrados, aspecto em que se revela o caráter ideológico dos signos e se põe na superfície o foco dado à linguagem e à mensagem no estudo da história. HW (I985) postula ser nisso que reside a ficcionalidade da história. A genialidade de um historiador, portanto, consiste não tanto em ele trazer novas informações ou descobertas em arquivos quanto na maneira como ele usa a linguagem e dirige a atenção para a construção de seu texto, alternando entre modos de explicação e representação (até mesmo entre estilos) e construindo uma atraente imagem verbal da realidade.

O texto se encerra tratando de Darwin, ponto em que são demonstradas mais algumas questões importantes. O biólogo inglês é outro autor que não está canonicamente definido como literário e é deslocado para esse campo por HW. Nisso, ele estabelece que amarrar os fatos uns aos outros e explicá-los requer procedimentos linguísticos - o diferencial do texto literário frente aos demais - que, em menor ou maior proporção, chamam a responsabilidade e a atenção não ao objeto, mas à mensagem, que tem forma pelo texto. No fim, acaba retomando a questão da retórica e sua diferença com a linguagem científica e com a linguagem cotidiana (prosaica), do que decorre a impossibilidade 
de se atingir uma linguagem objetiva como pretendida pelo marxismo, pelo positivismo e pela cliometria (WHITE, I985). O autor nota que cada tipo de discurso tem suas figuras com base nas funções que cumpre e que nisso reside a identificação entre o discurso da história e o da literatura.

Para se entender ficcionalidade em HW, cabe perguntar o que pode ser entendido a partir das ideias de construção, ficção e imagem verbal da realidade. Este texto realizará agora uma digressão às correntes teóricas que permitem iluminar esses termos, a saber: o romantismo e o formalismo russo. Essas filosofias não serão analisadas; apenas terão ressaltado o aspecto que aqui interessa, e o foco está mais na segunda do que na primeira.

\section{Conceito de ficção e sua aplicabilidade ao debate}

Os tópicos abaixo discutem o conceito de ficção em duas escolas importantes para esse debate na teoria da literatura e pretendem explorar sua aplicabilidade para o debate aqui relacionado.

\section{III.I. Ficção, romantismo e formalismo russo}

Para direcionar a leitura sobre essas duas abordagens, será antes levada a cabo uma definição sobre como se entende o termo ficção. O Dicionário Aurélio da Língua Portuguesa ${ }^{3}$ define ficção como "I. Ato ou efeito de fingir; simulação, fingimento. 2. Coisa imaginária; fantasia, invenção, criação". Fingir e imaginar conduzem à noção de mimese, a que Aristóteles (I999) assinalou como "imitação criativa" da realidade - algo mais específico do que a filosofia. A mimese busca as verdades universais em um caminho alternativo ao da filosofia.

O que aqui importa, do romantismo, é apenas a origem da ideia de arte pela arte. O sentido que alguns poetas e teóricos românticos atribuem à expressão será sumariamente abordado para que se possa tratar da noção de análise formal, encorpada no século XX. Deve ficar claro, desde já, que aqui não se pretende entender o romantismo ou estudar sua teoria, mas apenas explorar um conceito que tem importância para a crítica desenvolvida por HW.

Para os românticos, o conhecimento da realidade só pode ser atingido subjetivamente, distanciando-se do mundo objetivo. Portanto, por meio da

3 FERREIRA, I975, p. 625. 
recordação e da interiorização. Devem-se apagar os sentidos para que se obtenha o contato direto com a verdade - daí a predileção pelo gênero lírico, pelas imagens noturnas e pela poesia feita sob o efeito de alucinógenos (por exemplo, o Kubla Khan, de Coleridge ${ }^{4}$, fruto de um sonho tido sob o efeito do ópio). A arte e os sentidos aguçados oferecem acesso a outro mundo, mais real do que aquele onde o ser humano se encontra. Naturalmente, em um contexto em que o prestígio das ciências puras crescia exageradamente (o historiador imediatamente se lembra de Ranke ${ }^{5}$ no começo do século XIX, e HW também falou sobre isso em uma nota), a proposta romântica teve pouco eco.

Por se tratar de um período da história em que a divisão do trabalho se encontra em ponto avançado na Europa, o artista pode ou deve se preocupar apenas com a produção artística e nada mais. Com isso, a preocupação da arte pode se elevar até muito além de questões meramente cotidianas, prosaicas. Isso conduz à ideia da arte pela arte em sua maneira mais radical, na qual a arte não tem a ver com nada que não ela mesma. Baudelaire (I976, p. 333) anunciaria que a poesia "não tem como objeto a verdade, ela não tem senão a Si mesma". Para ele, o que se busca pela arte é algo superior ao mundo real. A arte é mensageira de um bem e uma verdade que não se encontram senão dentro dela mesma, na qual predominam os sentidos em detrimento da razão.

Essa visão permite formular o fenômeno da criação como composto por três elementos: o artista, o objeto e, entre eles, a obra e seu material transformado (a tinta em figuras humanas no caso da pintura, a palavra em figuras de linguagem no caso da poética etc.). Além disso, Oscar Wilde (apud TODOROV, 2009) mais tarde observaria que a arte ambiciona à criação de um mundo muito mais belo e atraente do que aquele em que se vive. Para Terry Eagleton (2006), o uso da palavra "imaginário" para designar a literatura pelo romantismo inglês faz referência a algo tanto inverídico quanto visionário ou inventivo. A obra de arte, de todo modo, pode e deve ser observada em sua autonomia com relação a todas as outras coisas.

A teoria da arte no século XX tem como momento decisivo de sua abertura o formalismo russo, cujo principal manifesto foi o ensaio de Viktor B.

4 COLERIDGE, S. T. Kubla Khan. Disponível em <https://www.poetryfoundation.org/poems-and-poets/poems/detail/4399I >. Acesso em: 2I abr. 20 I7.

5 Leopold von Ranke, I795-I886, foi um historiador prussiano associado ao naturalismo e à escola histórica. É considerado o pai da historiografia moderna. Foi o primeiro historiador profissional (dono de cadeira universitária propriamente designada para o curso) e defendia a objetividade de sua narrativa alegando que apenas relatava as fontes oficiais em detalhe e conforme a vontade de Deus. Opunha-se ao imaginativo, ao romance histórico, e alegava mostrar o passado como ele foi de fato. 
Shklovsky "Art as device" (I9I7) ${ }^{6}$. Shklovsky argumenta que a arte se realiza pelo procedimento (прием) de manipulação de uma matéria viva e existente. Eikhenbaum (I925) postularia que a forma não se apresenta ao conteúdo como receptáculo, mas molda a maneira como ele se oferece à percepção humana - o que condiz com a proposta artística do futurismo russo de que a forma determina o conteúdo (formulação atribuída ao poeta Aleksei Kruchenykh $^{7}$ ). A forma, e não o assunto, é determinante na arte. Para Shklovsky, no caso da arte poética, o que se manipula é a palavra. Por procedimento entende-se a forma de reorganizar ou alterar a ordem canônica de expressão linguística de modo a se produzir um efeito de estranhamento no leitor. Pode ocorrer do menor ao maior plano da linguagem de uma obra.

Nesse sentido, o texto poético é um uso estranho da língua e acaba chamando atenção para si próprio. O leitor diante da arte não pode pensar da mesma maneira como o faz no cotidiano, seguindo a lei do mínimo esforço. Não se pode ler um texto artístico mecanicamente, ou da mesma maneira com que se comporta rotineiramente. A arte se move na contramão da rotina, para romper com o automatismo. Acostumado a uma mesma forma de comunicação, o homem mata a língua. A arte inova no uso linguístico e exige que se desfaça do "mínimo esforço". Ela torna o mundo estranho, provoca o estranhamento (ostraneniye, остранение - neologismo em russo: deixar de ter com algo uma relação morna). Com isso, permite que se olhe o mundo, que se o perceba quando antes só se o via, nas palavras de Shklovsky. O artista é como uma criança: desloca o óbvio de sua cadeia de associações e desregula o cotidiano de quem já se acostumou com ele ${ }^{8}$. A literatura não é tão mimese quanto poiese para essa chave.

Tendo lido Shklovsky, Antoine Compagnon (2006) sugere que, de acordo com essa definição, a publicidade seria o auge da poética. Essa provocação faz refletir sobre o objetivo da arte. Enquanto a propaganda pretende vender (ou, no mínimo, divulgar) um produto, uma marca ou um conceito, a arte é autorreferencial. O objetivo de uma obra artística é ser uma obra artística. Esse é o limite entre os dois campos. Deixa de ser arte para ser propaganda tudo aquilo que se insinua com outro objetivo. O conteúdo

6 Há tradução em língua portuguesa desse texto na coletânea organizada por Dionísio de Oliveira Toledo, citada para os textos de outros formalistas. Optou-se pela versão em inglês devido à diferença de grafia entre as traduções nas duas línguas quanto ao nome do autor, uma vez que os dois outros textos de Shklovsky citados não têm tradução para o português.

7 TROTSKY, I922.

8 Nota de Shklovsky ao trabalho de Rozanov (SHKLOVSKY, 20I5). 
de um texto, para o formalismo, é ele mesmo, ou seja, a introdução de um personagem, motivo ou procedimento em um trabalho ficcional não busca ter um significado fora do texto, mas antes realizar uma ligação coerente entre uma parte e outra ou desacelerar a ação do enredo, realizar um tipo específico de construção textual etc. ${ }^{9} \mathrm{O}$ estudo das características que fazem de algo objeto literário consiste, portanto, não em procurar fora do texto a significação de suas partes, mas em analisar como um texto, gênero ou estilo se forma organicamente.

Esse trabalho de deslocamento tem relação com as funções da linguagem, segundo Jakobson (I960). Essa teoria é muito cara ao trabalho de HW e ele a retoma ao longo dos mais variados ensaios. De acordo com ela, o ato de comunicação exige emissor, contexto, receptor, canal, código e mensagem. Durante a comunicação, a oração pode estar "testando" algum desses fatores, e cada associação que ela faz realiza uma das funções da linguagem. Por exemplo: aquela que se volta para testar o canal é a função fática da linguagem quando se diz "alô" no telefone, ou "bom dia" em situação cotidiana. Volta-se para o código a função metalinguística, vista no tópico anterior. A arte é a língua em sua função poética: está voltada para a mensagem. Por meio da complicação, ela chama atenção para si própria e, consequentemente, para a imagem que cria de si.

Este foi o sumário da parte dessa teoria que interessa para que este artigo possa entender a ficção e seu estudo. Essa base teórica pode ser verificada na produção de HW, e este artigo a utilizará para iluminar o conceito de ficção. A próxima seção discute se é possível entender a história nessas bases.

\section{III.II. Sobre o conceito de ficção e sua aplicabilidade à história}

Cumpre voltar ao conceito de ficção com base no que foi exposto acima. Como fingimento, ela se apresenta como autossuficiente, invenção que chama a responsabilidade e a atenção para si mesma com o intuito de abrir os olhos do interlocutor para algo em específico da língua e, potencialmente, do mundo real. Não tem, a princípio, objetivo exterior a si: trata-se de uma criação independente, que não precisa ser associada nem ao real nem ao falso, ficando

9 Essa ideia fica essencialmente demonstrada por Shklovsky em sua análise do Don Quixote (cf. SHKLOVSKY, 2OI5b). 
como meio termo entre ambos ${ }^{\mathrm{IO}}$. Seus caminhos todos se completam sem deixar pontas soltas. De qualquer modo que se opte por entrar em contato com a ficção, ela se sustenta por si, mas ilumina, mesmo que não se queira, algum aspecto do mundo real, já que fissura o intermediário entre o homem e o mundo (a língua).

Nota-se, de passagem, que para um dos principais mestres de HW, Northrop Frye (1973), a verdade da arte deve ser entendida não alegoricamente (como ligada a dados de realidade), mas hipoteticamente, ou seja, como algo que o ser humano é capaz de conceber e que é coerente com suas próprias referências. Fantasmas em Hamlet não sugerem a existência de fantasmas no mundo real; sugerem que, na história de Hamlet, há fantasmas, e sua inclusão é justificada composicionalmente. O texto ficcional, para Frye, deve ser como uma operação da matemática pura. Ele não precisa ser a realidade. Precisa que suas premissas se mantenham coerentes e que seu desfecho seja honesto para consigo mesmo.

Com isso, responde-se se pode um texto de história ser ficcional, e a resposta parece ser afirmativa. $\mathrm{O}$ passado não pode retornar e, mesmo que pudesse, precisaria ser organizado coerentemente pela narrativa para poder ser compreendido. O texto da história precisa apresentar uma hipótese coesa e coerente sobre o passado. Sua verdade está em sua hipótese ser uma construção justificada sobre os fatos. Quem o lê não deve buscar as informações enciclopédicas, mas antes uma imagem consistente criada conforme disposições estruturadas e figurativas de signos. Busca-se, no livro de história, uma construção de sentido nova, que possa trazer novas reflexões e construções linguísticas relativas ao passado. Principalmente porque o historiador parte do pressuposto de que seu leitor já conhece os eventos narrados - assim como as tragédias da fase mítica grega.

Parece, por exemplo, absurdo supor que os eventos narrados em $O$ dezoito brumário de Luiz Bonaparte, de Karl Marx, jamais aconteceram - foram inventados, fantasiados, fingidos. Até porque Marx escreveu esse texto no calor dos acontecimentos. O importante nesse trabalho não são os eventos, mas a interpretação do autor, dada pela forma como ele organiza e caracteriza os fatos. $O$ dezoito brumário é relevante pelas conclusões a que chega, pelo texto que constrói. Ele não deve chamar atenção para as brigas políticas no interior da luta de classes na terceira república per se, mas para a política como teatro, o que se estabelece pelo uso de metáforas relativas ao jogo de cena, pela construção de planos

Io A formulação é de Todorov (I980). 
paralelos como bastidor-palco-público e por outros procedimentos. Compreende-se a história mais pela imagem verbal que ela tem a oferecer sobre a realidade do que pelas informações factuais e descobertas relativas a arquivos. O argumento de Marx não está, segundo HW (I973, p. 320-330), pronto nas fontes tomadas sozinhas, mas no modo metonímico como Marx os prefigura. Isso o permite interpretar os fatos de modo a dividir o segundo império nas quatro fases que narram uma tragédia da burguesia como fenômeno que dá abertura à possível comédia do proletariado, a revolução.

Se for assumido que a história é ficcional, isso significa que os fatos e as fontes a que recorrem os pesquisadores não têm em si nenhum significado intrínseco, como se argumentou acima. Antes, recebem seu acabamento por parte da pesquisa, que as une por um fio comum de sentido e uma determinada carga semântica dotada pelo objetivo da investigação. Essa liberdade ou licença poética cumpre o supracitado papel de estranhamento, uma vez que dá figuras e construções novas a antigos temas da história. A imagem criada pelo texto da história não corresponde ao passado em si, mas a um deslocamento semântico que reforma construções já gastas na língua para se referir aos eventos passados. Sua relação é mais com as outras obras do que com o passado, embora isso não implique questionar que a temática de um trabalho sobre história tenha necessariamente de ser algo que aconteceu de fato. Uma obra historiográfica busca causar estranhamento no leitor acostumado com determinadas construções já fixas no vocabulário, para com isso dar nova intensidade ao sentido do evento histórico ${ }^{\text {II }}$, o que se realiza a partir de construções no texto. O próprio HW (I973, p. 6, grifos do autor) nota que

Unlike the novelist, the historian confronts a veritable chaos of events already constituted, out of which he must choose the elements of the story he would tell. $\mathrm{He}$ makes his story by including some events and excluding others, by stressing some and subordinating others. This process of exclusion, stress, and subordination is carried out in the interest of constituting a story of a particular kind ${ }^{12}$.

II O texto já citado de Jakobson sobre o realismo discute a renovação do vocabulário como procedimento da arte. Nesse trabalho, ele estabelece que a arte se faz na relação entre as diferentes construções de texto (obras). Daí o realismo se opor às demais caracterizações: não por exigir um determinado tratamento da matéria da vida, mas por exigir uma motivação consequente e a justificação de seus procedimentos (cf. JAKOBSON, I978).

I2 Mais adiante, HW dá material para comparar essa formulação com a distinção proposta por Tomachevski (I925) entre fábula e trama (story and plot; skaz i syuzhet), também discutida por Eikhenbaum em seu ensaio sobre Gogol. A primeira se refere à sucessão de facto dos eventos e a segunda a como se organizam em um enredo a ser apreendido pelo leitor. Os arquivos, o passado sobre o qual se debruça 
Tomachevski (I925) já anunciara que o sucesso de um texto literário não se deve a seu tema, e sim à maneira como ele é elaborado. No caso da história, pode-se fazer a mesma afirmação. Desse modo, a inovação na história depende menos do tema do que de sua ficção, de seu acabamento verbal. Um historiador atinge seus objetivos não por descobertas em arquivos, mas por oferecer uma nova figuração linguística a um tema já conhecido, que lhe confere nova intensidade.

Nada parece se opor à ideia de que o conceito de ficção seja adequado para designar a história. É nisso que reside seu valor cognitivo: o de apresentar conclusões, no texto, válidas por elas mesmas. O valor da narrativa está em fazer sentido a partir da realidade, que, sozinha, é incompreensível. Parece ocorrer dessa maneira a aplicabilidade do conceito trazido por HW (I985).

Essa discussão conduz a um inevitável diálogo com outras interpretações sobre a obra de HW. Podem-se citar as de maior visibilidade. Jacques Le Goff (I990, p. 35) realiza uma breve análise de Metahistory (I975) para ilustrar o que ele chama de "terceira consequência abusiva que se extraiu do papel do particular em história". No caso, ele se refere ao fato de que a história ambiciona o universal a partir da descrição, narração ou análise de fatos particulares, singulares, irrepetíveis, e examina a ideia de que a história seja um conto, uma narrativa. Le Goff teme as reduções que o estruturalismo de HW pode trazer ao considerar o metier do historiador sob essa gramática narrativa - ponto que não foi aqui discutido - e chega a uma conclusão similar à que se ambicionou neste artigo. O autor afirma, seguindo Duby e Ladreau (I980 apud LE GOFF, I999), que é possível integrar a obra histórica no campo da arte, mas ela "não é uma obra de arte como as outras, [...] tem sua especificidade" (DUBY apud LE GOFF, I990, p. 38). Este artigo ratifica o que Le Goff implica ao citar de Roland Barthes a frase "a narração histórica morre porque o signo da história é, daqui em diante, menos real que o inteligível" (BARTHES, I967, apud LE GOFF, I990, p. 38), fato que, como este ensaio procurou sugerir, motiva a utilização de novas construções relativas a um mesmo tema. Aqui, procurou- se ir além do que Le Goff identifica em HW como sendo uma redução do trabalho de historiador a meras escolhas estilísticas para demonstrar até que ponto essas escolhas são elas mesmas construtoras de conhecimento histórico.

Também Carlo Ginzburg (20I4) traz conclusões relevantes que podem ter diálogo com este trabalho. Para ele, importa a princípio o quanto de ma-

um historiador, podem ser colocados na categoria da fábula, enquanto o trabalho de seu texto seria a elaboração da trama. 
terial histórico se pode extrair de uma narrativa - inventada ou não. Na introdução de sua obra, Ginzburg aponta que a verdade não é o ponto de partida, mas de chegada de toda narrativa. A relação entre a história e a literatura lhe interessa na medida em que um pode ser revelador do significado do outro. Ginzburg não hesita, inclusive, em citar um estudioso de literatura, Erich Auerbach, cuja obra referência é Mimesis, a estudar a literatura para dela retirar conclusões relativas à sociedade em que é produzida, ver os "rastros" que ela deixou em seu caminho pelos labirintos do tempo. Ginzburg também analisa a problemática implicação do humanismo de HW em seu capítulo sobre o holocausto. Aproxima o pensamento do estudioso norte-americano a suas raízes no idealismo italiano e verifica como ele define "verdade" - interessante contraponto para o que aqui foi chamado de ficção. Tratar-se-ia de ver o termo como sinônimo de eficácia, ou seja, tudo aquilo que pode assumir "efeito de verdade". Os perigos do humanismo de HW não foram aqui estudados. De maneira resumida, o argumento de Ginzburg consiste em dizer que a concepção de HW o deixa desamparado diante das possibilidades de uma narrativa historiográfica vinda da extrema direita, o que ele mesmo busca combater. Também acusa sua concepção do campo histórico como o Sublime de ter ligação com pensadores fascistas. Ginzburg demonstra pouca familiaridade com o trabalho de HW, porque o próprio já havia se defendido dessas acusações (I987), e também o defendem alguns de seus comentadores (PAUL, 2OII; DORAN, 2OIO).

Existem questionamentos cabíveis à ficcionalidade da história quando se trata de sua relação com os fatos. É o caso das colocações de Eric Hobsbawm (I998), para quem o termo ficção alude a algo que não está sujeito a verificações. Este artigo procurou iluminar temores desse tipo. A preocupação de Hobsbawm é digna de nota e de feliz acerto: não se pode permitir que, pela ideia de ficção, fatos jamais ocorridos passem por história. Quando este artigo examinou brevemente a distinção entre fábula e trama proposta por Tomachevski, as provas, os documentos e os arquivos examinados pelo historiador foram cautelosamente incluídos no terreno da fábula sem que, com isso, se perdesse a distinção básica entre um livro de história e um romance. A "fábula" do historiador é radicalmente diferente da fábula da arte poética. Hobsbawm (I998, p. 3) estabelece que algumas coisas invariavelmente aconteceram: "Roma derrotou e destruiu Cartago nas Guerras Púnicas, e não o contrário". Pelo que ficou demonstrado neste texto, considerar a história como ficção do fato não significa dizer que o historiador pode sustentar que Cartago tenha dominado Roma. Significa dizer que a história, como disciplina, busca novas significações - sensíveis a partir de formulações de ordem linguística - em 
fatos a partir de reorganizações de ideias e figurações, ora novas para suas épocas, ora conservadoras - os tipos de trama estudados por HW. Isso não autoriza a produção da história sem o recurso às fontes, afinal isso reduziria sua operação apenas ao estágio da trama, e não existe trama sem fábula. Não são os fatos que devem ser desconsiderados ao se afirmar a "ficção do fato". É a possibilidade de se falar deles sempre da mesma maneira. Tampouco essa consideração implica discordar da ideia de que os trabalhos em história podem ser unidos por uma mesma linha quanto a seus projetos, como assinala Hobsbawm. Em defesa de HW, deve-se atentar para o fato de que sua análise observa os modos de se relacionarem os eventos na linguagem dos historiadores; o que conta para a pesquisa e para o argumento de cada um e o que participa ou não do campo histórico. Em nenhum momento ele se posiciona contra a pesquisa documental - muito pelo contrário. Sua análise vai observar que diferentes modos figurativos produzem significados diferentes sobre o mesmo conjunto de eventos.

No campo acadêmico brasileiro, é digno de nota o trabalho de Sidney Chalhoub (I998), que trava diálogo com HW de maneira semelhante à de Ginzburg: com atenção aos rastros deixados pela literatura no terreno da história e vice-versa. Para esse autor, toda obra literária é passível de ser interrogada como documento histórico). A história pode tomar a literatura como sua fonte de análise. Esse é seu primeiro ponto. O segundo é que toda obra literária deve ser localizada em seu espaço e tempo na história - principalmente social. Este artigo procurou demonstrar que também é válida a inversão dos papéis, e que a literatura poderia estar autorizada a analisar as formas da história nas mãos dos historiadores.

\section{Considerações finais}

Este artigo procurou discutir o conceito de ficção trazido por HW e sua aplicabilidade em história e literatura. Para tanto, começou expondo o conceito de ficção factual trazido pelo autor em "The fictions of factual representation", que consiste na criação de uma imagem verbal da realidade. Na sequência, apresentou uma conceituação própria da ideia de ficção, recortando-a dos referenciais teóricos que antecedem e dão respaldo ao trabalho de HW, com foco principalmente no formalismo russo. Ficou demonstrado que o termo ficção alude a fingimento, invenção, que parte da realidade para representá-la em uma distorção que force o contemplador da arte a estranhar seu uso cotidiano da língua e a perceber novos sentidos em antigos assuntos. Ficção 
ficou também definida como algo que, para formalistas como HW, tem autorreferencialidade e busca dar sentido à realidade. Por fim, observou-se que é possível considerar a história como ficção do fato na medida em que isso signifique observá-la como hipótese coerente e com sentido sobre seu tema (o passado). Para concluir, foi feito breve paralelo com historiadores que se debruçam sobre o tema, visando a demonstrar como essa abordagem, do ponto de vista da teoria literária, pode ter algo a contribuir.

Escrever algo novo sobre um tema da história significa, em vez de trazer informações novas, no sentido de arquivos, realizar novas associações, novos deslocamentos semânticos, novas formas. Uma descoberta na história se define por inovar a percepção sobre um determinado objeto, e isso só é possível a partir de construções de caráter linguístico - a partir da ficção. Chamar a história de ficção do fato implica considerá-la uma hipótese verossímil sobre um tema do passado.

\section{Referências}

ARISTÓTELES. Poética. In: PESSANHA, J. A. M. (Org.). Os pensadores: Aristóteles. I. ed. São Paulo: Nova Cultural, I999.

CHAlHOUB, S. Apresentação. In: CHAlHOUB, S.; PEREIRA, L. A. M. (Orgs.). A História contada: capítulos de história social da literatura no Brasil. Rio de Janeiro: Nova Fronteira, I998. p. 7-I3.

COMPAGNON, A. A Literatura. In: O Demônio da teoria: literatura e senso comum. Belo Horizonte: Editora UFMG, 2006. p. 29-47.

DORAN, R. Editor's Introduction. In: WHITE, H. The Fiction of Narrative: Essays on History, Literature, and Theory (I957-2007). Baltimore/London: The Johns Hopkins University Press. 20I0. p. xiii-xxxii.

EAGLETON, T. Teoria da literatura: uma introdução. 6. ed. São Paulo: Martins Fontes, 2006.

EIKHENBAUM, B. M. A teoria do "Método Formal". In: TOLEDO, D. O. (Org.). Teoria da literatura: formalistas russos. 4. ed. Porto Alegre: Globo, I978. p. 3-38.

FRYE, H. N. Ethical criticism: theory of symbols. In: Anatomy of criticism: four essays. Princeton: Princeton University Press. Third Printing, I973. p. 7I-I28.

GINZBURG, G. O fio e os rastros: verdadeiro, falso, fictício. São Paulo: Cia. das Letras, 20I4.

HOBSBAWM, E. Sobre história. São Paulo: Cia. das Letras, I998. 
JAKOBSON, R. O. Linguística e poética. In: Linguística e comunicação. São Paulo: Cultrix, I96o. p. II8-I62.

. Do realismo artístico. In: TOLEDO, D. O. (Org.). Teoria da literatura: formalistas russos. 4. ed. Porto Alegre: Globo, I978. p. II9-I27.

LE GOFF, J. História. In: História e memória. Campinas: Unicamp, I990. p. I7-I66.

PAUL, H. Hayden white: the historical imagination. Cambridge/Malden: Polity Press, $201 \mathrm{I}$.

SHKLOVSKY, V. B. Art as device. In: . Theory of prose. 6th printing. Champaign/London/Dublin: Dalkey Archive Press, 20II. p. I-I4. Literature without a plot: Rozanov. In: Theory of prose. 6 th printing. Champaign/London/Dublin: Dalkey Archive Press, 20II. p. I89-205. . The making of Don Quixote. In: . Theory of prose. 6 th printing. Champaign/London/Dublin: Dalkey Archive Press, 20II. p. 72-IOO.

TODOROV, T. A literatura em perigo. 2. ed. Rio de Janeiro: Difel, 2009.

TROTSKY [Lev Davidovich Bronstein]. A escola poética formalista e o marxismo. In: TOLEDO, D. O. (Org.). Teoria da literatura: formalistas russos. 4. ed. Porto Alegre: Globo, I978. p. 7I-85.

A noção de literatura. In: Os gêneros do discurso. São Paulo: Martins Fontes, I980. p. II-23.

TOMAGHEVSKI, B. V. Temática. In: TOLEDO, D. O. (Org.). Teoria da literatura: formalistas russos. 4. ed. Porto Alegre: Globo, I978. p. I69-204.

WHITE, H. V. Tropics of discourse: essays in cultural criticism. 2. ed. Baltimore/ London: The Johns Hopkins University Press, I985. . Metahistory: the historical imagination in nineteenth century Europe. Baltimore/London: The Johns Hopkins University Press, I975. The Politics of Historical Interpretation: Discipline and De-Sublimation. In: The Content of the Form: Narrative Discourse and Historical Interpretation. Baltimore: The Johns Hopkins University Press, I985. p. 58-82.

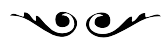

Henrique Carvalho Pereira é graduando em História pela Universidade de São Paulo e graduando em Letras pela Pontifícia Universidade Católica de São Paulo.

pereirahenriquec@gmail.com 